\title{
Early eclosion of overwintering cotton bollworm moths from warming temperatures accentuates yield loss in wheat
}

\author{
Fang Ouyang ${ }^{\mathrm{a}}$, Cang Hui ${ }^{\mathrm{b}, \mathrm{c}}$, XinYuan Men ${ }^{\mathrm{d}}$, YongSheng Zhang ${ }^{\mathrm{a}, \mathrm{e}}$, Lipeng Fan ${ }^{\mathrm{a}}$, \\ Peijian Shi ${ }^{\mathrm{f}}$, Zihua Zhao ${ }^{\mathrm{g}}$, Feng Ge ${ }^{\mathrm{a}, *}$ \\ a State Key Laboratory of Integrated Management of Pest and Rodents, Institute of Zoology, Chinese Academy of Sciences, Beijing 100101, China \\ ${ }^{\mathrm{b}}$ Centre for Invasion Biology, Department of Mathematical Sciences, Stellenbosch University, Matieland 7602, South Africa

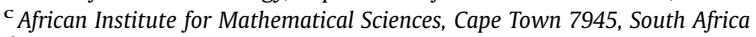 \\ d Institute of Plant Protection, Shandong Academy of Agricultural Sciences, Jinan 250100, China \\ e College of Plant Protection, Hunan Agricultural University, Changsha 410128, China \\ ${ }^{\mathrm{f}}$ Institute of Bamboo, Nanjing Forestry University, Nanjing 210037, China \\ g Department of Entomology, College of Plant Protection, China Agricultural University 100193, China
}

A R T I C L E I N F O

\section{Article history:}

Received 23 August 2015

Received in revised form 5 October 2015

Accepted 3 November 2015

Available online 14 November 2015

\section{Keyword:}

Climate change

Helicoverpa armigera

Population dynamic

Time series

Asymmetrical effect

\begin{abstract}
A B S T R A C T
Understanding and predicting the impact of climate change on population demography, biotic interactions and ecosystem service is central to ecology. Long-term time series analysis of insect populations is crucial for analyzing the effect of climate change on plant-insect interactions in agroecological systems; yet such data are often lacking. Here, based on field experiments and the long-term time series of the overwintering adult cotton bollworm Helicoverpa armigera (Hübner) (Lepidoptera: Noctuidae) collected since 1975, we investigate the dynamic trend of $H$. armigera, as well as its driving forces and effects on the recruitment of $H$. armigera and crop yield. Results illustrated a shift to early eclosion of diapausing pupae due to global warming, extending the duration and abundance of adults in the overwintering generation. This then led to more larvae recruited in the first generation, and consequently damages the wheat at early growing stages. Our results suggest that the asynchronous effects of rising global surface temperature on the relative growth rate of spring crops and insect pests could intensify in the future, causing accentuated crop yield loss. To mitigate the adverse herbivoremediated effect on crop yield in a warming climate, efficient cultivation measures and pest management are necessary, such as planting precocious crops with short growth period and timely control of insect pests.
\end{abstract}

(c) 2015 Elsevier B.V. All rights reserved.

\section{Introduction}

Understanding and predicting the impacts of anthropogenic climate change on population demography, biotic interactions and ecosystem services is fundamental in current ecology (Jamieson et al., 2012). The climate can influence plants and insects through a variety of physiological and phenological processes, including metabolism, reproduction, growth, development and migration behavior (Durant et al., 2007). The impacts of climate change, however, include both direct effects on plant and insect demography and indirect effects through cross-trophic interactions (Brown et al., 1998; Coley, 1998; Massad and Dyer, 2010). Knowing the potential response of insects to climate change and

\footnotetext{
* Corresponding author. Fax: +86 1064807099

E-mail address: gef@ioz.ac.cn (F. Ge).
}

the effect of climate change on plant-insect interactions helps us to better formulate pest management strategies or tactics (Ladányi and Horváth, 2010; Jamieson et al., 2012). To this end, long-term time series of insect populations plus field experiments are crucial for elucidating the effect of climate change on plant-insect interactions in agroecological systems, and yet such data is often lacking.

Climate change poses one of the most serious challenges to the sustainability of agroecological systems (Zilberman et al., 2002). Effects of climate change on plant/pest populations rely on the integral of climate and other related factors such as soil moisture (Fuhrer, 2003). Temperature is identified as the dominant abiotic factor affecting herbivorous insects (Bale et al., 2002); it has a direct effect on ontogenetic development, survival, and reproduction of insects, as well as an indirect effect on generation time and population growth rate (Forster et al., 2011). Warm temperatures often have a positive effect on the abundance of insect populations. 
For example, warm temperatures and low annual precipitation favor the outbreak of mountain pine beetle (Dendroctonus ponderosae) in the southern Rocky Mountains (Chapman et al., 2012). Warm temperatures halved the reproductive time of the Spruce beetle (Dentroctonus rufipennis) (Berg et al., 2006a). Warm temperatures combined with the occurrence of dry summers have triggered the outbreak of Ips typographus, one of the most destructive pests of European spruce forests (Marini et al., 2012). The overwintering mortality of adult Nezara viridulaand Halyomorpha halys can be reduced by $15 \%$ with $1{ }^{\circ} \mathrm{C}$ rise of temperature (Kiritani, 2006). Warm temperatures can also have a positive effect on the productive potential of crops, leading to an extended growing season and thus an increase in crop yield (Shaver et al., 2000; Veteli et al., 2002; Fang et al., 2003, 2004; Peng et al., 2011). However, the indirect herbivore-mediated effect on plants under warming temperatures is poorly studied in agroecological systems.

Besides affecting insect abundance and crop yield, temperature can also affect the traits of interacting species, such as the timing of different life stages in insects and plants (Taylor, 1986; Roberts et al., 2015; Wheeler et al., 2015). Analyses of the consequences of temperature-driven shifts in phenology-the timing of life cycle events, such as the oviposition, hatching, pupation and emergence of insects, and the sprouting, flowering, fruiting of plants, can trace their conceptual origins to the match/mismatch hypothesis (Parmesan and Yohe, 2003; Root et al., 2003). The concept of match/mismatch stems from fisheries biology to understand why the survival of cod and other commercial fish species at their early stages is critical (Durant et al., 2007). The match/mismatch hypothesis (MMH) seeks to explain the recruitment variation in a population by the synchronous phenology of the focal species and its resource (Cushing, 1969). As the response of the timing or duration of ontogeny (plants and insects) to temperature changes can be diverse (Yang and Rudolf, 2010), species interactions as a result can change, decouple or even strengthen over the entire span of their life cycles (Richardson et al., 2013). Studies on the effect of global warming on the phenology of plants and insects has increased dramatically since the 1980s, but only few were examining the effect in agricultural systems (Jamieson et al., 2012). The knowledge gap of how the interactions between insect pests and crops respond to global warming through matching/ mismatching phenology needs to be filled.
The adult moth of the cotton bollworm, Helicoverpa armigera (Hübner) (Lepidoptera: Noctuidae), is one of the most damaging crop pests in Asia (Ge et al., 2005), America (Gujar and Kalia, 2005; Tay et al., 2013), Africa and Europe (Nibouche et al., 1998), characterized by its polyphagy, high mobility, high fecundity, and facultative diapause (Wu and Guo, 2005). It can have four generations per year in northern China (Ge et al., 2005), with the wheat, Triticum aestivum as the host crop for the firstgeneration (G1) larvae, while other three targeting major crops such as corn, cotton, peanut and bean (Wu and Guo 2005). For instance, the outbreak of its second and third generations (G2 and G3 hereafter) in the early 1990s caused a drastic decline of cotton yield in northern China (Wu and Guo, 2005), showing its peak in 1992 (Ouyang et al., 2014).

Since 1997 transgenic cotton with a gene from the bacterium Bacillus thuringiensis (Bt) has been widely planted to combat $H$. armigera outbreaks in China. Large-scale cultivation of Bt cotton has contributed more to the reduction of ovular and larval densities in G2 and G3 bollworms than climatic variations ( $\mathrm{Wu}$ et al., 2008). A Bt cotton diet can further weaken the coldhardiness of larval in the overwintering generation (G0), consequently reducing the density of G1 bollworms of the following year (Ouyang et al., 2011). However, weakening density dependence from climate change and agricultural intensification can trigger pest outbreaks, highlighting the importance of exogenous factors to safeguarding the population regulating mechanism of negative density dependence (Ouyang et al., 2014). It is therefore of both theoretical and practical value to elaborate regulators of population dynamics for $H$. armigera and the effects of indirect herbivoremediated interactions on crop yields in a warming environment.

Here, we investigate how changes in abundance and timing of the life stages of G0 $\mathrm{H}$. armigera from global warming can influence wheat biomass. Based on a long-term time series of G0 H. armigera moth collected since 1975, plus a controlled experiment, we explore the temporal trends in $H$. armigera population dynamics, and their causes and consequences. Our aim is to sequentially address four interrelated issues: (1) detect long-term temporal trends of the G0 cotton bollworm moth; (2) analyze the temporal trends of the local climate; (3) determine the cause of early eclosion in G0 moths; (4) quantify the effect of early eclosion in G0 moths on wheat biomass loss.

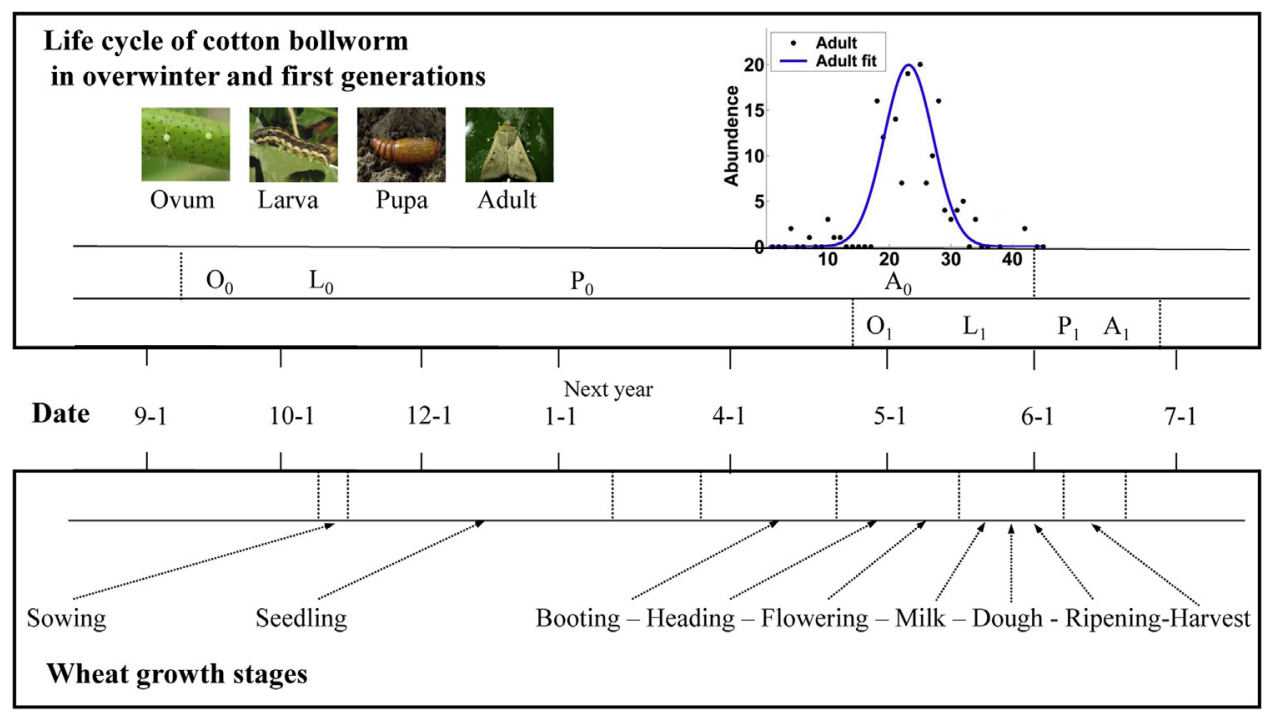

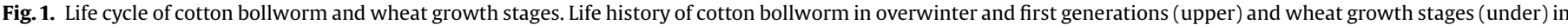

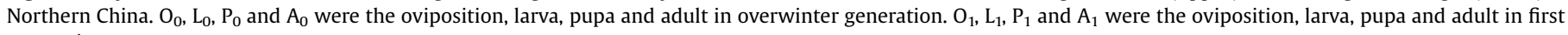
generation. 


\section{Materials and methods}

\subsection{Time series analyses}

The study region is at Raoyang County $\left(38^{\circ} 05^{\prime}-38^{\circ} 20^{\prime} \mathrm{N}\right.$, $115^{\circ} 34^{\prime}-115^{\circ} 55^{\prime} \mathrm{E}$ ) in Hebei Province of China, which has four distinct seasons and dominated by farmlands (Ouyang et al., 2014). Major crops in the study region include wheat, corn, peanut, soybean, sorghum, cotton and cole. Local daily temperature $\left({ }^{\circ} \mathrm{C}\right)$ was acquired from the China Meteorological Data Sharing Service System (http://cdc.cma.gov.cn). Specifically, local daily mean temperature is the mean temperature at 2:00, 8:00, 14:00 and 20:00 of each day. Mean temperature is the mean of the local daily mean temperature during the overwinter period from 1 November to 30 April. Accumulative total temperature is the accumulated value of below-zero temperatures per day during the overwinter period. H. armigera has four generations per year in the study area (Ge et al., 2005; Ouyang et al., 2014). Each generation has four instars, including ovum, larva, pupa and adult moth (Fig. 1). The
(A)

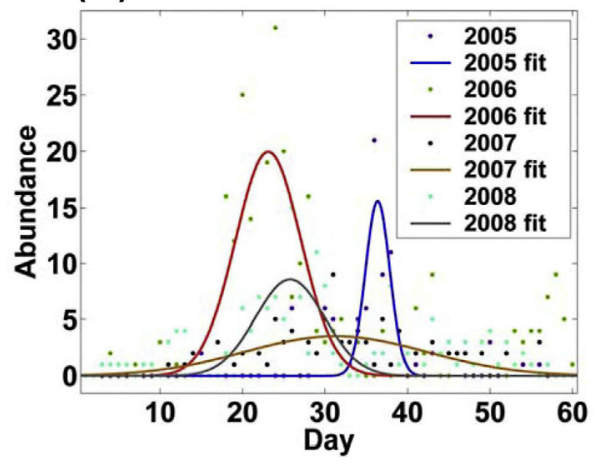

(C)

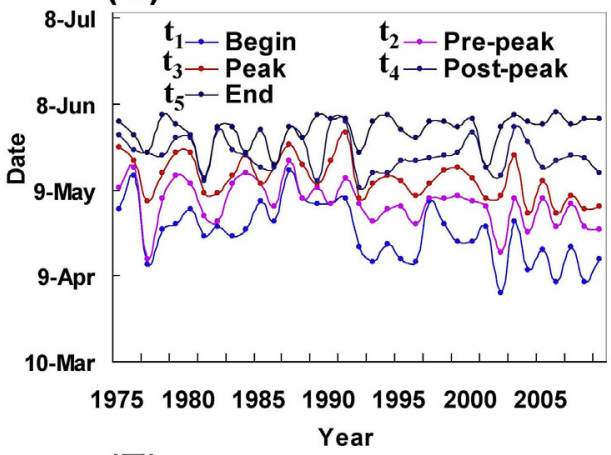

(E)

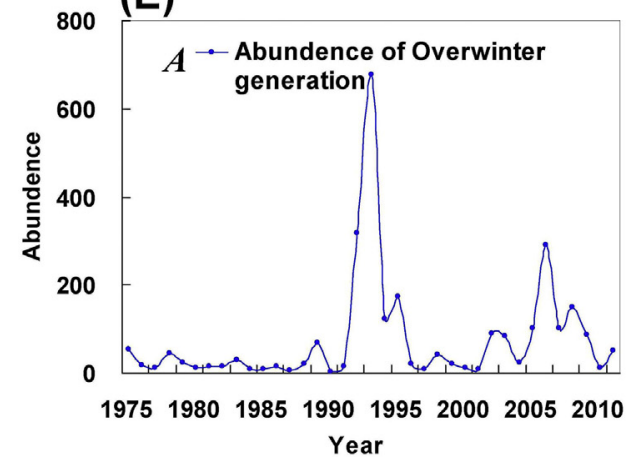

G1 larvae of $H$. armigera emerge from early May to late June and mainly target wheat as the host crop, while other three generations target all major crops (Wu and Guo, 2005). The G0 diapause pupae stay in soil with low temperatures from late October to late April of the following year (Fig. 1). Upon eclosion, the abundance of G0, G1, G2 and G3 moths were monitored using light traps with fluorescent lamp at night since 1975 (till 2011) at Raoyang County were located at Wugong Village before 2001 and moved to Baichi Village afterward, $10 \mathrm{~km}$ apart, from dusk (18h00) to dawn (06h00) every day from early April to the end of September. The monitoring of moths was conducted according to the national standard for pest investigation and forecast of the cotton bollworm.

The number of G0 moths captured daily within a year follows a normal function curve (Fig. 3A). The changes in abundance, eclosion date and duration of G0 adult moths were obtained from fitting the daily catch to a Gaussian (normal) function:

$f(t ; A, T, \delta)=\frac{A}{\sigma \sqrt{2 \pi}} e^{-(t-T)^{2} /\left(2 \delta^{2}\right)}$,
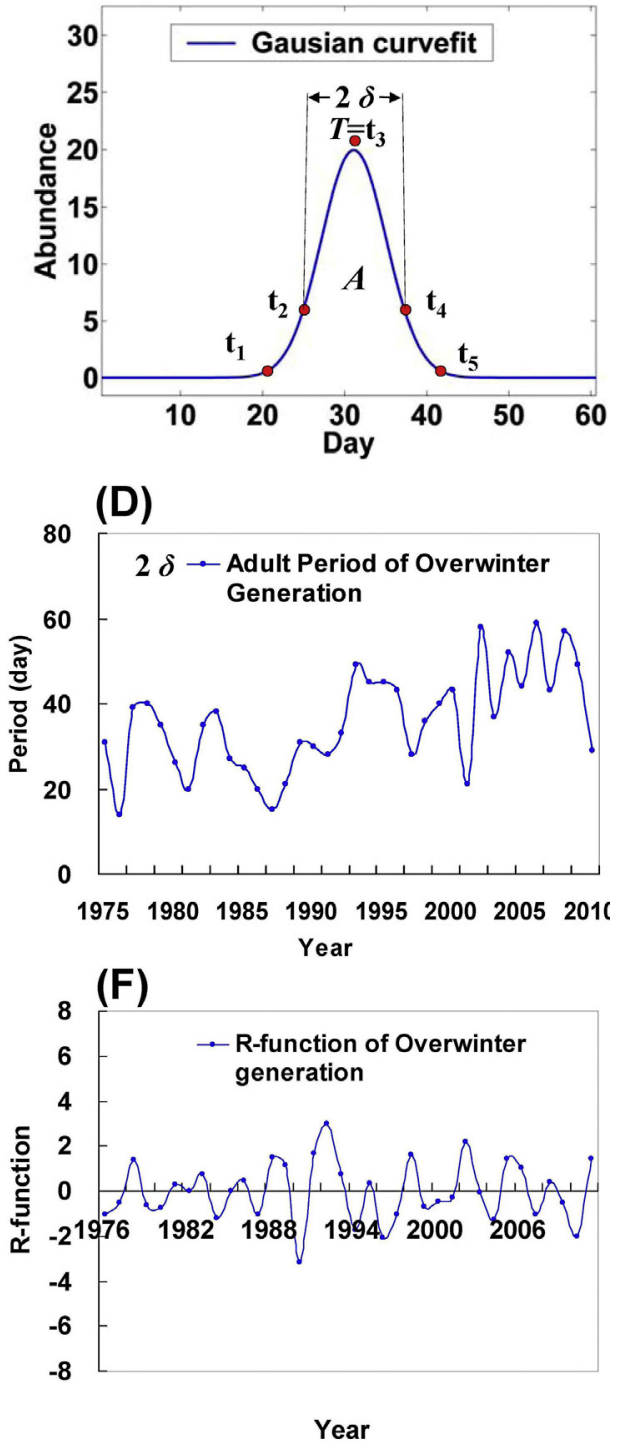

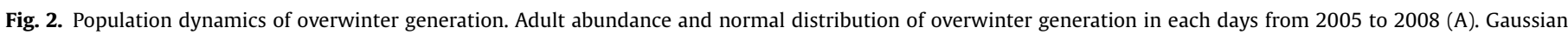

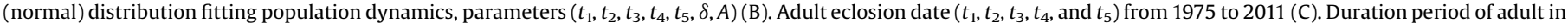

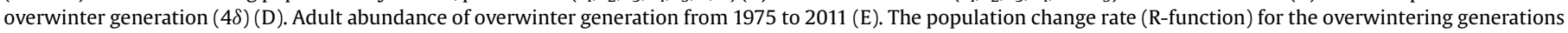


where $t$ represents the day, $A$ the area under the curve (i.e., the abundance of moths; Fig. $2 \mathrm{~A}$ ), $T$ the date of the maximum moth abundance, and $2 \delta$ an indicator of the duration of G0 moths. Based on the character of a normal distribution (Limpert et al., 2001), we further defined $t_{1}, t_{2}, t_{3}, t_{4}$, and $t_{5}$, respectively, as the first eclosion date, pre-peak date ( $15.85 \%$ eclosion), peak date (50\% eclosion), post-peak date ( $84.15 \%$ eclosion) and the last eclosion date (Fig. 2B, Table 1). Parameters were estimated using MATLAB 7.5 (MathWorks, 2007).

For the time-series analysis, we calculated the relative growth rate of $H$. armigera (Turchin, 1999) using the $R$-function (Berryman and Turchin, 2001), $R_{i}=\operatorname{Ln}\left(N_{i} / N_{i-1}\right)$, where $N_{i}$ is the abundance of G0 moths at year $i$ and $N_{i-1}$ the abundance of G3 moths at year $i-1$, respectively. Trends of the eclosion date $\left(t_{1}, t_{2}, t_{3}, t_{4}, t_{5}\right)$, duration $(2 \delta)$, abundance $(A)$ and relative growth rate $(R)$ were analyzed from 1975 to 2011. Refer to analysis method of Ouyang et al. (2014), trends of temperature (mean temperature, and accumulated total temperature below zero) during the overwinter period from October to next April in study site from 1975 to 2011 were also analyzed. Relationships between the temperature and the G0 eclosion date, duration, abundance and relative growth rate were estimated. All trends and relationships were examined using the generalized linear model (GLM) in the SPSS v17 (SPSS Inc, Chicago, IL, USA).

\subsection{Field experiment}

We used the wheat in the field experiment as the main host plant of $H$. armigera. The life cycle of wheat, from sowing to harvest in northern China, was list in Fig. 1. From the growing stage of booting to ripening, wheat suffers from the G1 larvae of $H$. armigera hatched from the eggs laid by the G0 moth (Fig. 2). We obtained wheat seeds from the Chinese Academy of Agricultural Sciences and planted on 10 Oct 2012 (Fig. 1) in a 0.5 ha field without pesticides at the Agricultural Experiment Station of Raoyang County (Fig. 6). All plants were watered and fertilized following the agricultural routine of the region. The $\mathrm{G} 1$ larvae of $H$. armigera were placed on wheat at eight different days in separate plots from 27 Apr to 25 May in 2013, respectively (Fig. 6). We made sure that the larvae of the same age were released at each application date and in each plot. Specifically, we released 200 larvae of the 2 nd instar per plot and had eight plots as repeats per five days. Each plot was covered with a nylon net $(2 \mathrm{~m} \times 1.0 \mathrm{~m} \times 2 \mathrm{~m})$ to prevent the escape of larvae or predation from natural enemies. An additional eight plots of wheat with nylon nets were used as the control. After the harvest, we estimated the total biomass $(\mathrm{g})$, wheat stalk $(\mathrm{g})$, wheat ear $(\mathrm{g})$ and wheat grain (g) of each plot (Fig. 6A). One-way ANOVA using the Student-Newman-Keuls (SNK) test was performed for multiple comparisons. The framework and ways in this study was list in Fig. S1.

\section{Table 1}

Temporal trends of appearance date, abundance and relative growth rate of overwintering cotton bollworms from 1975 to 2011.

\begin{tabular}{llllll}
\hline Parameter & Linear regression & $R^{2}$ & $P$ & Trend \\
\hline$t_{1}$ & The first eclosion date & $Y=-0.4512 X+922.3$ & 0.2130 & 0.0050 & $\downarrow$ \\
$t_{2}$ & Pre-peak date & $Y=-0.2484 X+528.4$ & 0.1137 & 0.0440 & $\downarrow$ \\
$t_{3}$ & Peak date & $Y=-0.3167 X+673.2$ & 0.2152 & 0.0040 & $\downarrow$ \\
$t_{4}$ & Post-peak date & $Y=-0.1115 X+272.7$ & 0.0355 & 0.2710 & $\searrow$ \\
$t_{5}$ & The last eclosion date & $Y=-0.1838 X-307.2$ & 0.1178 & 0.0400 & $\downarrow$ \\
$2 \delta$ & Period & $Y=0.7249 X-1408.1$ & 0.3844 & $<0.0001$ & $\uparrow$ \\
$\mathrm{A}$ & Abundance & $Y=2.4519 X-4812.3$ & 0.0411 & 0.2360 & $\nearrow$ \\
$\mathrm{R}$ & R-function & $Y=0.0046 X-9.1797$ & 0.0013 & 0.8340 & $\sim$ \\
\hline
\end{tabular}

$X$, year from 1975 to $2011 ; Y$, parameters in population dynamics of overwinter generation; $\downarrow$ or $\uparrow$ indicates significant decrease or increase at $p<0.05$; \} \text { and } \nearrow indicate no significant trend; $\sim$ indicates fluctuation around 0 .

\section{Result}

\subsection{Population dynamics}

The eclosion timing $\left(t_{1}, t_{2}, t_{3}, t_{4}, t_{5}\right)$, duration $(2 \delta)$, abundance $(A)$ and relative growth rate $(R)$ of G0 moths from 1975 to 2011 were presented in Fig. 2. There was a significant shift towards earlier dates of the first eclosion $\left(t_{1}\right)(F=9.2, P=0.005, \mathrm{df}=1,34$ [df is the same hereafter unless states otherwise]), pre-peak eclosion $\left(t_{2}\right)$ $(F=4.36, P=0.044)$, peak eclosion $\left(t_{3}\right)(F=9.33, P=0.004)$ and the last eclosion $\left(t_{5}\right)(F=4.54, P=0.04)$; the post-peak eclosion was also shifted towards earlier but not significant $\left(t_{4}\right)(F=1.25, P=0.27)$ (Fig. 2C, Table 1 ). The duration of G0 moths was also significantly prolonged $(2 \delta) \quad(F=15.85, P<0.001$, Fig. $2 \mathrm{D}$, Table 1$)$. The abundance of G0 moths $(A)$ showed a slight increase $(F=1.46$, $P=0.24$, Fig. 2E, Table 1$)$. The relative growth rate fluctuated around zero with no clear trends $(R)$ (mean $\pm \mathrm{SE},-0.002 \pm 0.223$; $t_{35}=-0.007, P=0.83$; Fig. $2 F$ ). During the same period, the mean overwinter temperature has shown a significant increase $(F=25.06, P<0.001$, Fig. $3 \mathrm{~A})$, with an increment of $1.7^{\circ} \mathrm{C}$. Accumulated overwinter temperature also increased significantly $\left(F=5.697, P=0.023\right.$, Fig. 3B), with an increase of 155.3 day ${ }^{\circ} \mathrm{C}$.

Analysis using the GLM showed that increasing mean overwinter temperature has significantly shifted the eclosion to earlier dates $\left(t_{1}, F=12.54, P=.001\right.$, Fig. $4 \mathrm{~A} ; t_{2}, F=8.36, P=0.007$, Fig. $4 \mathrm{~B} ; t_{3}, F=10.86, P=0.001$, Fig. $4 \mathrm{C} ; t_{4}, F=4.27, P=0.047$, Fig. $4 \mathrm{D}$ ). Increasing mean overwinter temperature has significantly increased the duration of G0 moths $(2 \delta)(F=20.59, P<0.001$, Fig. $5 \mathrm{~A})$. An increase of $1{ }^{\circ} \mathrm{C}$ could shift the ecolsion $\left(t_{1}, t_{2}, t_{3}\right.$ and $\left.t_{4}\right)$ to earlier dates by $7.2,4.7,4.8$ and 2.9 days, respectively, postpone the last appearance of G0 moths ( $t_{5}$ ) by 1.9 days (Fig. $3 \mathrm{~A}-\mathrm{E}$ ), and extend the duration by 9.9 days (Fig. $5 \mathrm{~A}$ ). Increasing accumulated overwinter temperature had the same effect of shifting the eclosion to earlier dates $\left(t_{1}, F=13.68, P=0.001\right.$, Fig. $4 \mathrm{~F} ; t_{2}, F=14.83, P=0.001$, Fig. $4 \mathrm{G}$; $t_{3}, F=18.17, P<0.001$, Fig. $4 \mathrm{H} ; t_{4}, F=5.09, P=0.03$, Fig. $\left.4 \mathrm{I}\right)$, prolonging the duration $(4 \delta)(F=10.37, P=0.003$, Fig. 4D), and boosting up relative growth rate $(R, F=4.36, P=0.044$, Fig. $4 \mathrm{~F})$. The abundance of adult $H$. armigera in the overwintering generation was significantly positively related to mean temperature $(F=5.2989, \quad \mathrm{df}=1,34, \quad P=0.028)$ and accumulated overwinter temperature $(F=4.4912, \mathrm{df}=1,34, P=0.042)$ during the overwinter period from 1975 to 2011, after removing the outlier of 1993 outbreak. Mean temperature and accumulated overwinter temperature explained close to $15 \%$ and $13 \%$ of the abundance variation, respectively, in the overwintering generation.

\subsection{Effect of cotton bollworms on wheat biomass}

The release dates of cotton bollworms significantly affected the total biomass (unit: $g$ ) of wheat after the harvest $(F=14.17, \mathrm{df}=1,8$ [the same hereafter], $P<0.001$, Fig. $6 \mathrm{~A})$, wheat stalk $(F=15.14$, $P<0.001$, Fig. 6B), wheat ear $(F=10.38, P<0.001$, Fig. $6 C)$ and wheat grain $(F=11.58, P<0.001$, Fig. $6 \mathrm{D})$. The total wheat biomass in plots with the cotton bollworm released on 21 May $(1879.75 \pm 78.40), \quad 17$ May $(1859.0 \pm 90.19)$ and 13 May $(1765.75 \pm 79.91)$ were significantly lower $(\mathrm{P}<0.01)$ than on 25 May $(2704.00 \pm 64.04)$. The total biomass in plots with the bollworm released on 27 April (1410.25 \pm 143.44$), 1$ May $(1270.75 \pm 58.39), \quad 5$ May $(1347.50 \pm 47.12)$ and 9 May $(1406.75 \pm 62.72)$ were significantly lower $(P<0.05)$ than on 13 May. The total biomass with bollworms released on 25 May showed no difference $(P=0.53)$ from the control $(3099.33 \pm 537.07$; Fig. 6 A). Bollworm release showed similar effects on the weights of wheat stalk (Fig. 6B), wheat ear (Fig. 6C) and wheat grain (Fig. 6D) (Table S1). 
(A)

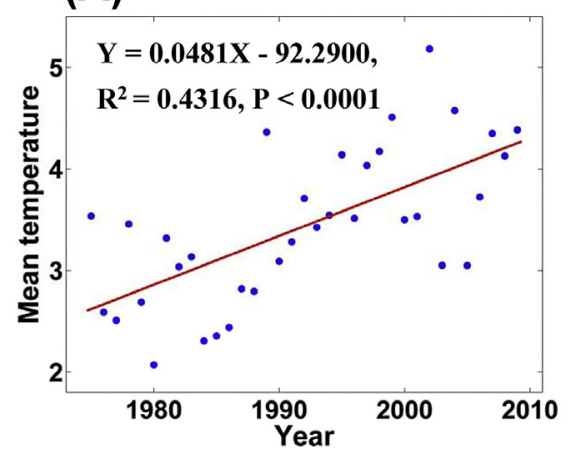

(B)

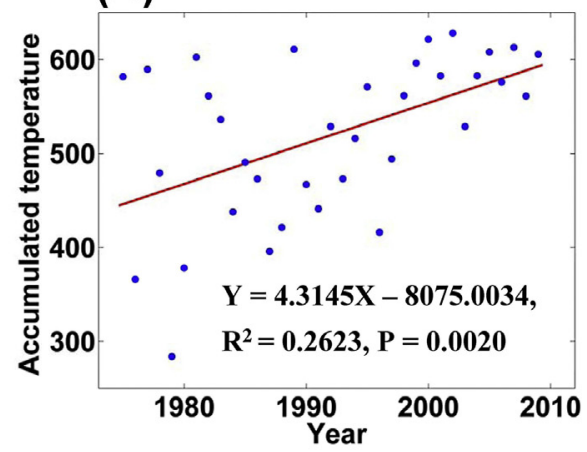

(C)

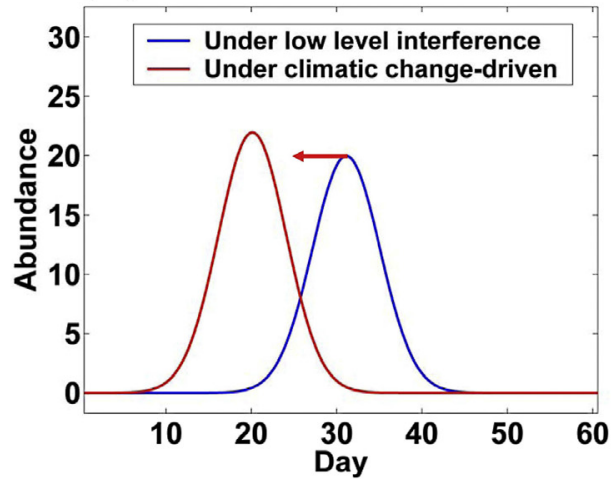

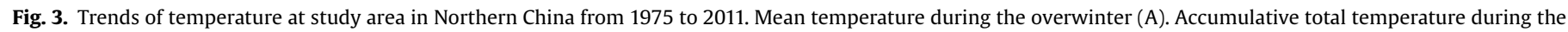
overwinter (B). Change trend of normal distribution in overwinter generation from under low level interference to under climatic change-driven (C).

\section{Discussion}

\subsection{Effect of climate change on bollworm population dynamics}

Climate change was evident in the past century (Stenseth et al. 2003; Prendergast, 2008), and ambient temperature has been identified the dominant abiotic factor that can directly affect the development, survival, dispersal and abundance of herbivorous insects (Bale et al., 2002; Kreyling, 2010; Cornelissen, 2011). Our results showed that the occurrence of $\mathrm{G} 0$ moths had been shifted to earlier dates from 1975 to 2011, and the duration of adult moths prolonged, with the abundance of G0 moths slightly increased. Similar results have been observed in the phenology of British butterflies (Roy and Sparks, 2000). The results showed that first appearance, pre-peak, peak, post-peak, and the last appearances of most British butterflies have shifted earlier from 1976 to 1998 and the duration of flight period extended (Roy and Sparks, 2000). Our results also found that increasing mean or accumulated overwinter temperature from 1975 to 2011 could have pushed for earlier dates of the first appearance $\left(t_{1}\right)$, pre-peak $\left(t_{2}\right)$, peak $\left(t_{3}\right)$ and post peak $\left(t_{4}\right)$, but delayed the last appearance $\left(t_{5}\right)$ of cotton bollworms.

In contrast to the advance of 2-10 days of the first and peak appearance in most British butterflies to respond to a $1{ }^{\circ} \mathrm{C}$ temperate rise (Roy and Sparks, 2000), the first, pre-peak, peak and post-peak appearance of cotton bollworms shifted earlier by 7.2, 4.7, 4.8 and 2.9 days, respectively, while the last appearance prolonged by 1.9 days (thus an extended duration of flight period by 9.9 days for G0 moths). Other studies have found similar phenological responses to temperature rise. For example, an analysis of a 40-year time series of flying aphids in Europe has revealed a strong relationship between aphid phenology and environmental variables (Harrington et al., 2007). Two important wasp species (Vespa crabroand Vespula germanica) in Poland have also appeared earlier since 1980s, especially in years with warmer springs (Tryjanowski et al., 2010). The average date of the first spring flight for 23 butterfly species in the Central Valley of California has shifted earlier during the past 31 years by 24 days (Forister and Shapiro, 2003).

Global warming not only can shift insect phenology but also the population dynamics of animals (Creel and Creel, 2009; Knape and de Valpine, 2011), especially insect pests (Ward and Masters, 2007; Guo et al., 2009; Logan et al., 2010). Indeed, changes in temperature can affect system stability and cause recurrent outbreaks of many pest insects such as tea tortrix (Adoxophyes honmai) in Japan (Nelson et al., 2013). Changes in temperature can also greatly influence the development and survival of cotton bollworms (Wu and Guo, 2005). Our previous study showed an enhanced population growth in G3 cotton bollworms from high summer temperature (Ouyang et al., 2014). Temperature is an important exogenous density-independent factor that can affect the survival of pupa in overwintering cotton bollworms. Here, we found that the abundance of G0 moths also slightly increased, with temperature explained $15 \%$ abundance variation after removing the outlier of 1993 outbreak. As the G0 diapausing pupae have to spend a long time with low temperatures in soil (Ouyang et al., 2011), increasing accumulated overwinter temperature can promote the development and thus move earlier the eclosion of pupae. Increasing mean overwinter temperature can also alleviate the stress of freezing conditions and thus enhance the survival of diapausing pupae. Consequently, global warming has resulted in earlier eclosion of pupae, extended duration of adult moths and increased abundance of G0 moths, which has potentially accentuated the damage from cotton bollworms to the first generation of wheat in the year. 
(A)

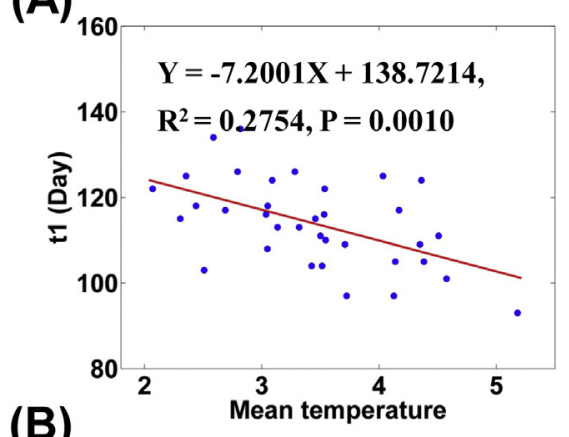

(B)

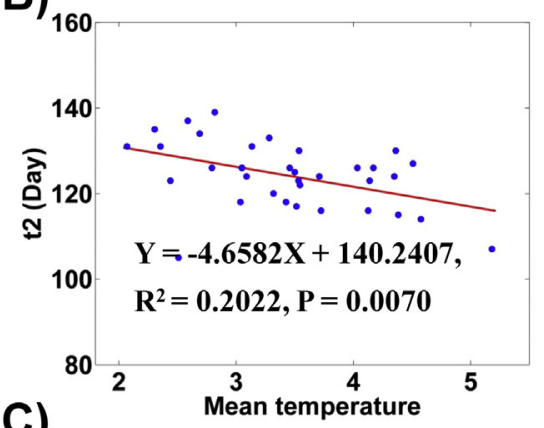

(C)
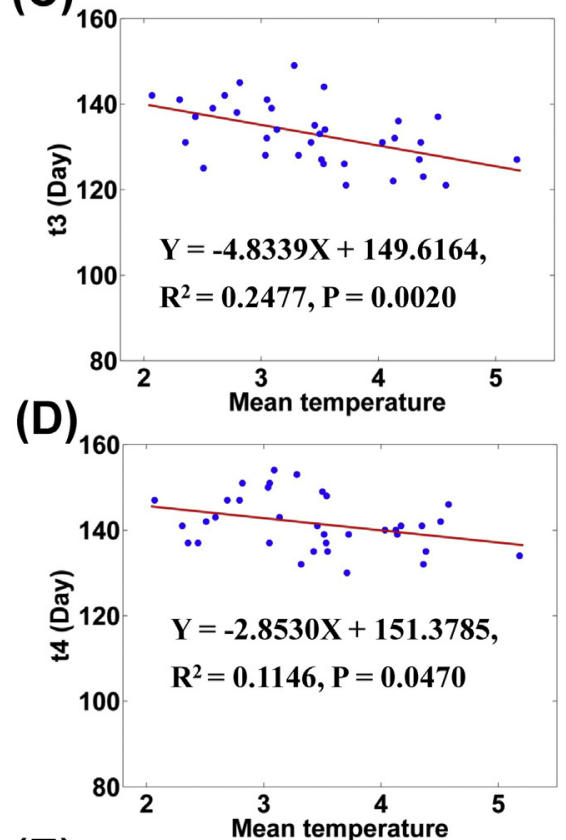

(E)

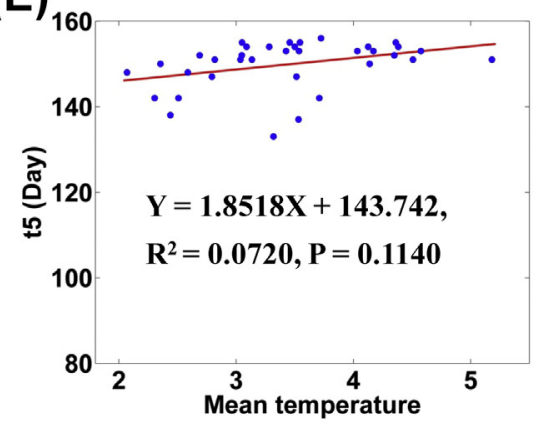

(F)

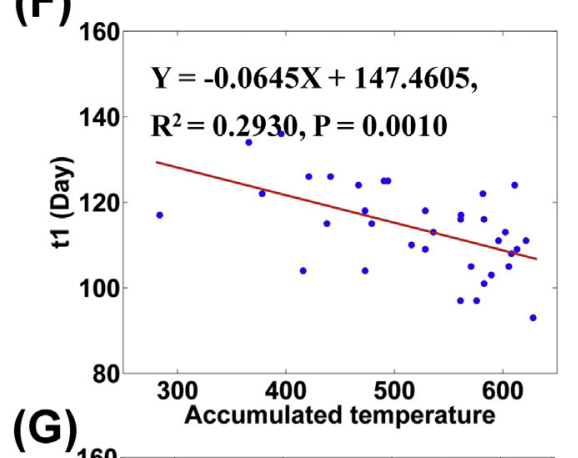

(G)

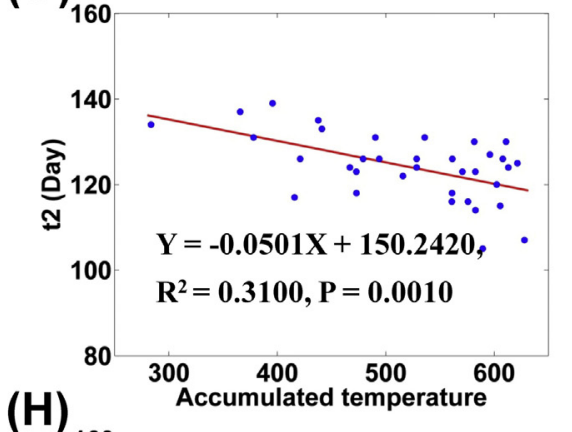

(H)

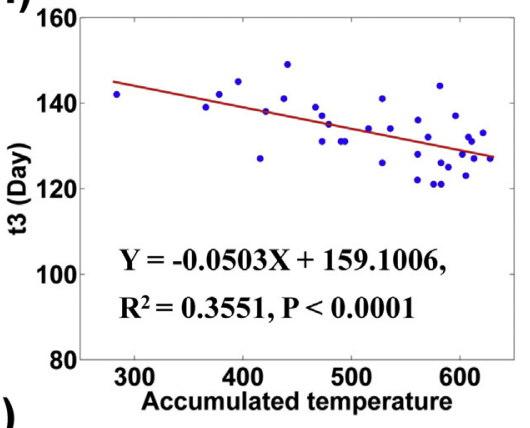

(I)

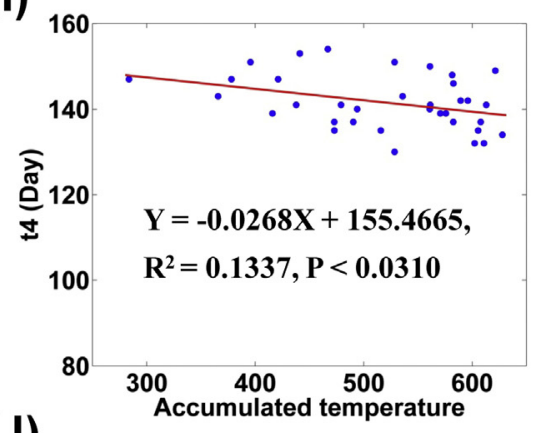

(J)

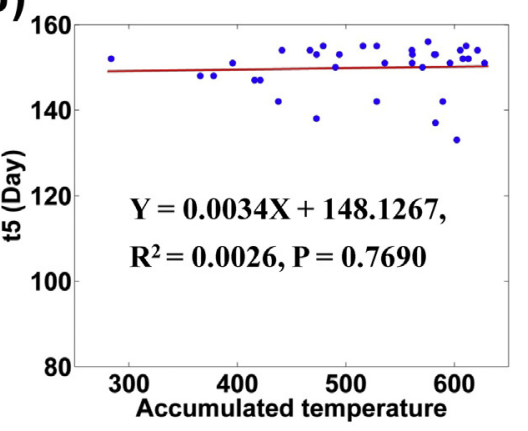

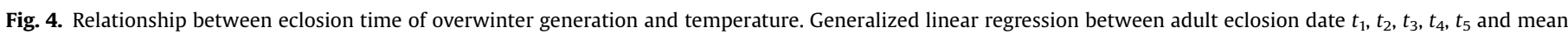

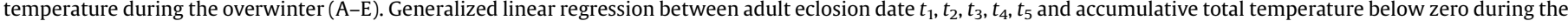
overwinter (F-J). 
(A)

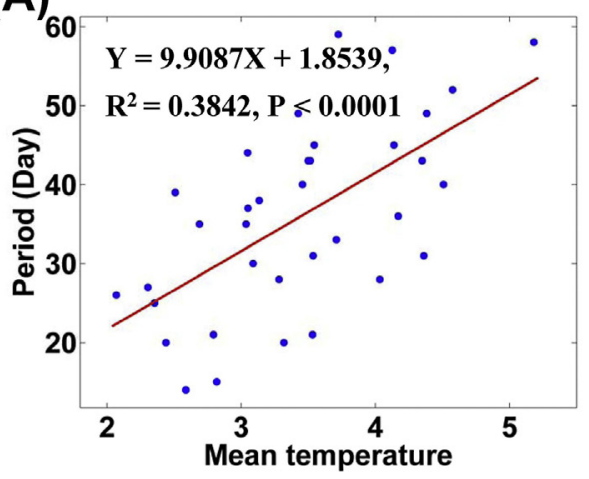

(B)

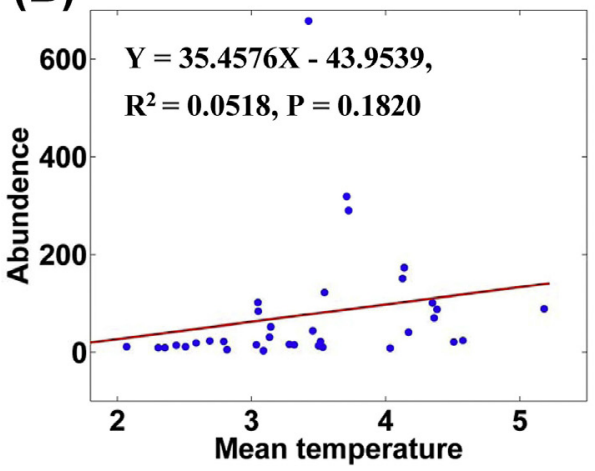

(C)

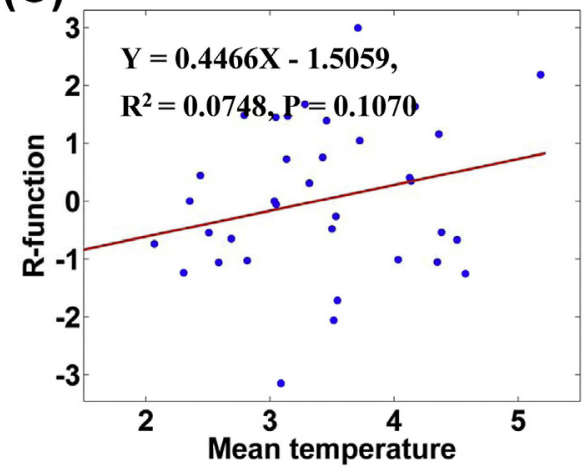

(D)

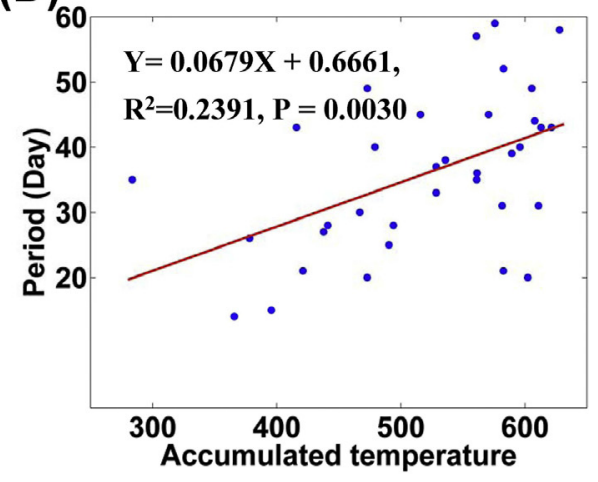

(E)

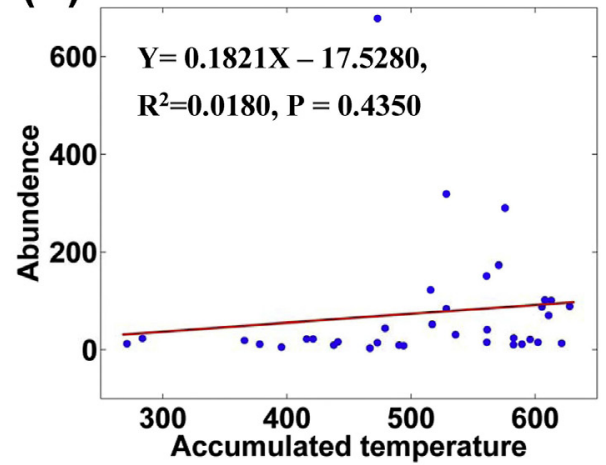

(F)

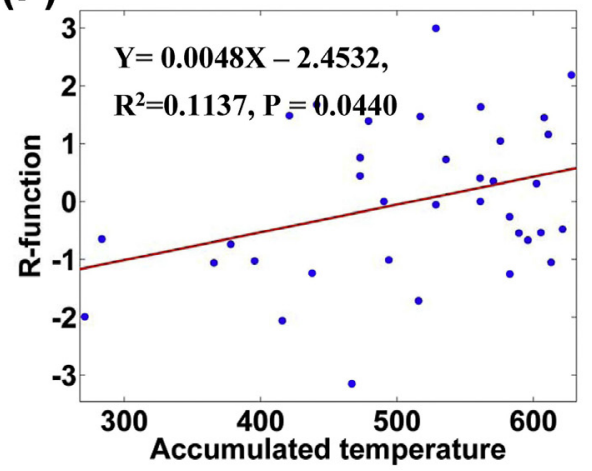

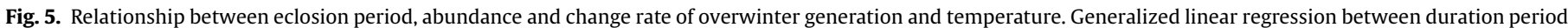

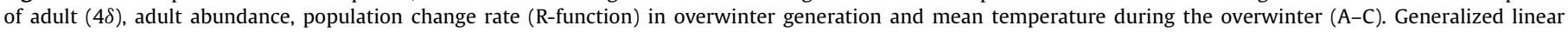

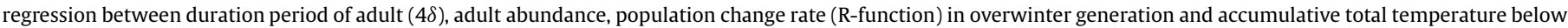
zero during the overwinter (D-F).

\subsection{Damage from cotton bollworms to wheat biomass}

Evidence of increased severity and extent of forest pest insect outbreaks, from climate change, is mounting (Kurz et al., 2008). For instance, in north-western North America, warmer temperatures have accelerated the reproduction of spruce beetles (Dendroctonus rufipennis Kirby, Coleoptera: Curculionidae, Scolytinae), causing unprecedented damages to spruce forests (Berg et al., 2006b). After the eclosion of diapausing pupae, G0 adult moths normally lay eggs on wheat as the host plant for G1 bollworms (Ge et al., 2005). G1 larvae can feed on the leaf tissue, straw, ear and grain of wheat from early May to late June, and during the same period wheat will also experience sequential growth stages of heading, flowering, milk, dough and ripening. Weights of stalk, ear, grain and total biomass suffered a heavier loss in plots exposed the cotton bollworm earlier.

\subsection{Effect of climate change on relative growth rate}

Climate can influence the population demography of a species directly via affecting reproduction, growth, migration behavior and phenology (Durant et al., 2007) or indirectly through affecting the interactions with its prey, predators and competitors (Cornelissen, 2011; Rogers, 2011; Jamieson et al., 2012). The concept of match/ mismatch can be applied to explore the relationship of phenology between wheat and $H$. armigera under climate change. Because insect metabolism is more sensitive or faster than plant metabolism to temperature increases, insect development should respond more swiftly to global warming (Bale et al., 2002; Berggren et al., 2009; Jamieson et al., 2012). As H. armigera feeds on a wider diet from the third instar (Ge et al., 2005), the G1 larva could target the growth stages of heading, flowering, milk, dough and ripening. An increase of $1{ }^{\circ} \mathrm{C}$ could shift earlier the first and peak appearances of G0 moths by 7.2 and 4.8 days, respectively, with more eggs of G1 $H$. 

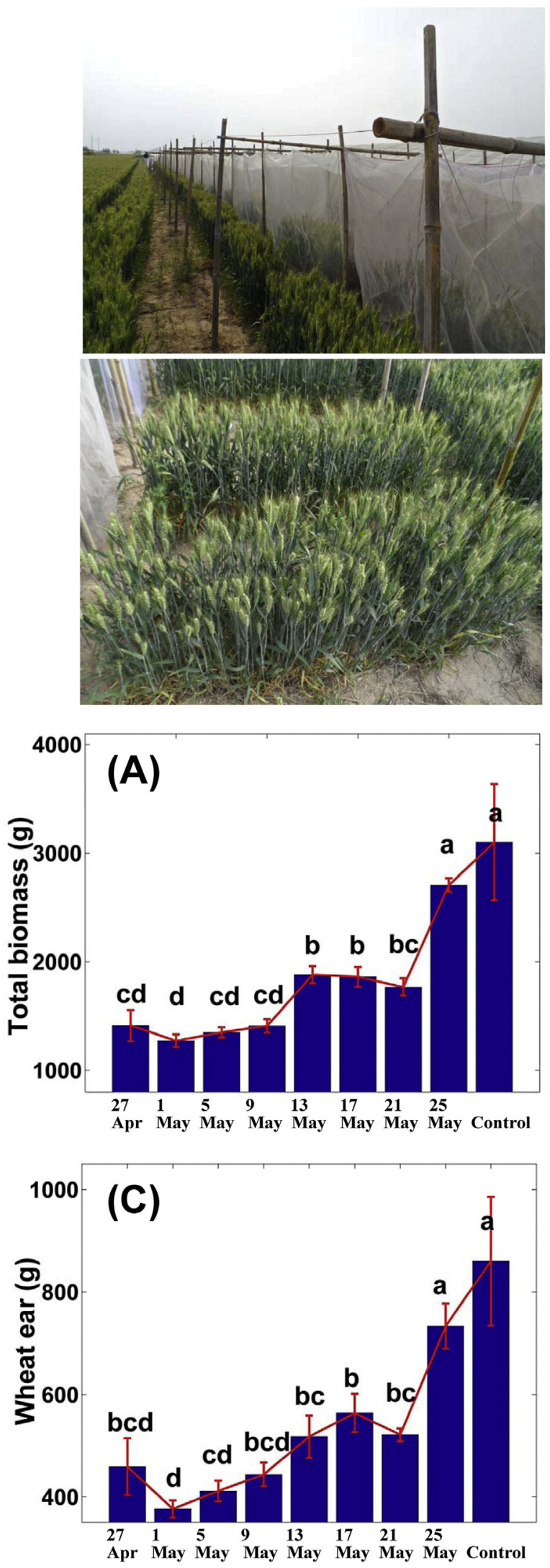
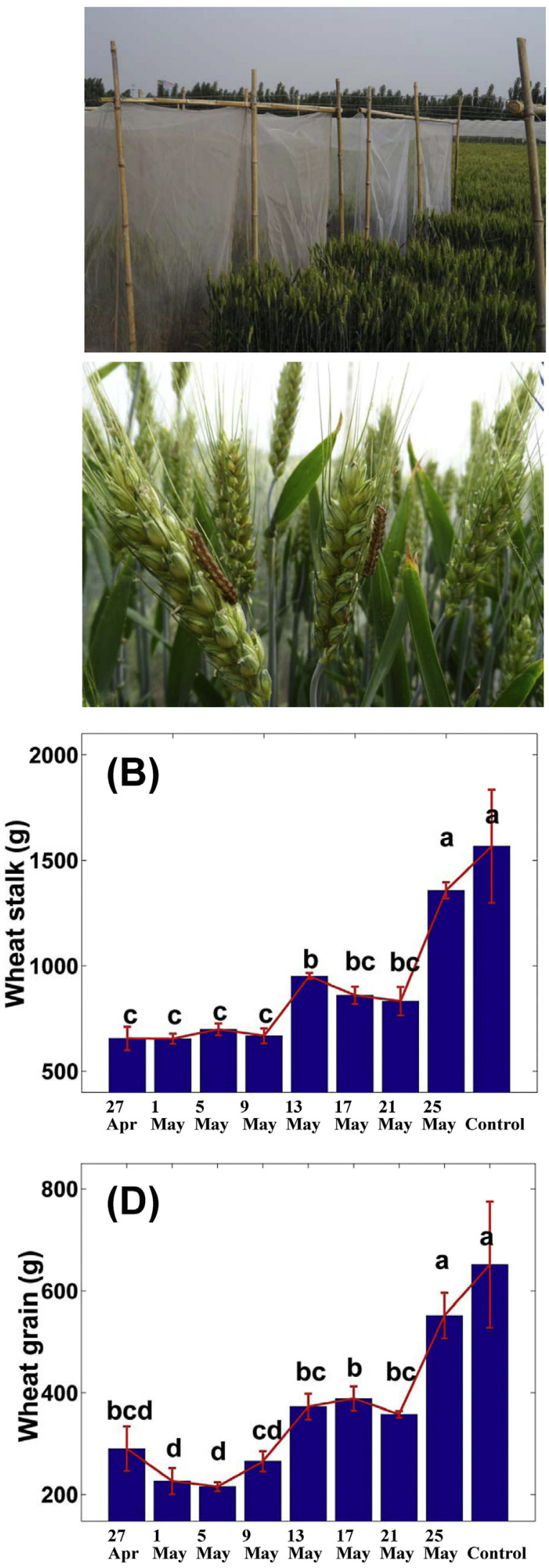

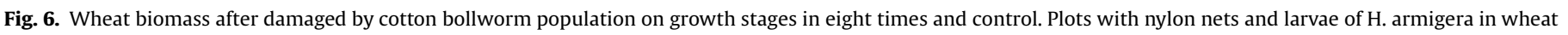

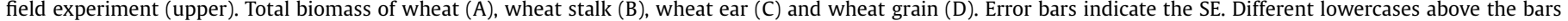
indicate significant differences in wheat biomass in eight times and control at $p<0.05$. 
armigera entering into their larval stage earlier. Compared to the advance of wheat growth under global warming, $H$. armigera could respond more swiftly, and its G1 larvae are more likely to shift the damage the to early growth stages of wheat.

\section{Conclusion}

Our results suggest that warm winters and springs have shifted the eclosion of overwinter pupal of $H$. armigera to earlier dates, and the asynchronous responses in relative growth rate of wheat and $H$. armigera of $\mathrm{G} 0$ and $\mathrm{G} 1$ could accentuate the damage to wheat yield from global warming. The fourth IPCC report predicts that the global-average surface temperature could rise $4^{\circ} \mathrm{C}$ by 2100 (Schnoor, 2007). The asynchronous responses in crop and pest phenology to rising temperatures could keep widening. To avoid further adverse effect of ongoing temperature rising on crops, efficient cultivation measures and pest management are required. Planting precocious crops with a short growth period, together with timely pest control could be recommended.

\section{Acknowledgements}

This project was supported by the Strategic Priority Research Program of the Chinese Academy of Sciences (XDB11050400), National Nature Science Fund of China (No.31221091), National Key Technology R\&D Program (2012BAD19B05) and the National Research Foundation of South Africa (Grants 76912 and 81825).

\section{Appendix A. Supplementary data}

Supplementary data associated with this article can be found, in the online version, at http://dx.doi.org/10.1016/j.agee.2015.11.010.

\section{References}

Bale, J.S., Masters, G.J., Hodkinson, I.D., Awmack, C., Bezemer, T.M., Brown, V.K., Butterfield, J., Buse, A., Coulson, J.C., Farrar J. 2002. Herbivory in global climate change research: direct effects of rising temperature on insect herbivores. Glob. Change Biol. 8 (16), 1-16

Berg, E.E., Henry, J.D. Fastie, C.J., Volder, A.D.D., Matsuoka, S.M., 2006a. Spruce beetle outbreaks on the Kenai Peninsula, Alaska, and Kluane National Park and Reserve, Yukon Territory: Relationship to summer temperatures and regional differences in disturbance regimes. For. Ecol. Manage. 227, 219-232.

Berg, E.E., Henry, J.D., Fastie, C.L., Volder, A.D.D., Matsuoka, S.M., 2006b. Spruce beetle outbreaks on the Kenai Peninsula, Alaska, and Kluane National Park and Reserve, Yukon Territory: Relationship to summer temperatures and regional differences in disturbance regimes. For. Ecol. Manage. 227, 219-232.

Berggren, Åsa, Bjorkman, C., Bylund, H., Ayres, M.P., 2009. The distribution and abundance of animal populations in a climate of uncertainty. Oikos 118,1121 1126.

Berryman, A., Turchin, P., 2001. Identifying the density-dependent structure underlying ecological time series. Oikos 92, 265-270.

Brown, C., larke, W., hittaker, H., ollier, 1998. Direct and indirect effects of climate change on insect herbivores: Auchenorrhyncha (Homoptera). Ecol. Entomol. 23 , $45-52$.

Chapman, T.B., Veblen, T.T., Schoennagel, T., 2012. Spatiotemporal patterns of mountain pine beetle activity in the southern Rocky Mountains. Ecology 93, $2175-2185$

Coley, P.D., 1998. Possible Effects of Climate Change on Plant/Herbivore Interactions in Moist Tropical Forests. Springer, Netherlands, pp. 315-332.

Cornelissen, T. 2011. Climate change and its effects on terrestrial insects and herbivory patterns. Neotropical Entomol. 40, 155-163.

Creel, S., Creel, M., 2009. Density dependence and climate effects in Rocky Mountain elk: an application of regression with instrumental variables for population time series with sampling error. J. Anim. Ecol. 78, 1291-1297.

Cushing, D.H., 1969. The regularity of the spawning season of some fishes. ICES J. Mar. Sci. 33, 81-92.

Durant, J.M., Hjermann, D.O., Ottersen, G., Stenseth, N.C., 2007. Climate and the match or mismatch between predator requirements and resource availability. Clim. Res. 33, 271-283.

Fang, J.Y., Piao, S.L., Field, C.B., Pan, Y.D., Guo, Q.H., Zhou, L.M., Peng, C.H., Tao, S., 2003. Increasing net primary production in China from 1982 to 1999. For. Ecol. Manage. 1, 293-297.

Fang, J.Y., Piao, S.L., He, J.S., Ma, W.H., 2004. Increasing terrestrial vegetation activity in China, 1982-1999. Sci. China Ser. C: Life Sci. 47, 229-240.
Forister, M.L., Shapiro, A.M., 2003. Climatic trends and advancing spring flight of butterflies in lowland California. Glob. Change Biol. 9, 1130-1135.

Forster, J., Hirst, A.G., Woodward, G., 2011. Growth and development rates have different thermal responses. Am. Nat. 178, 668-678.

Fuhrer, J., 2003. Agroecosystem responses to combinations of elevated $\mathrm{CO}_{2}$, ozone, and global climate change. Agric. Ecosyst. Environ. 97, 1-20.

Ge, F., Chen, F.-j., Parajulee, M.N., Yardim, E.N., 2005. Quantification of diapausing fourth generation and suicidal fifth generation cotton bollworm, Helicoverpa armigera, in cotton and corn in northern China. Entomol. Exp. Appl. 116, 1-7.

Gujar, G.T., Kalia, V.K., 2005. Hemocyte diversity of the American bollworm Helicoverpa armigera. Phytoparasitica 33, 17-27.

Guo, K.U.N., Hao, S.-G., Sun, O.J., Kang, L.E., 2009. Differential responses to warming and increased precipitation among three contrasting grasshopper species. Glob. Change Biol. 15, 2539-2548.

Harrington, R., Clark, S.J., Welham, S.J., Verrier, P.J., Denholm, C.H., Hullé, M., Maurice, D., Rounsevell, M.D., Cocu, N., 2007. Environmental change and the phenology of European aphids. Glob. Change Biol. 13, 1550-1564.

Jamieson, M.A., Trowbridge, A.M., Raffa, K.F., Lindroth, R.L., 2012. Consequences of climate warming and altered precipitation patterns for plant-insect and multitrophic interactions. Plant Physiol. 160, 1719-1727.

Kiritani, K., 2006. Predicting impacts of global warming on population dynamics and distribution of arthropods in Japan. Popul. Ecol. 48, 5-12.

Knape, J., de Valpine, P., 2011. Effects of weather and climate on the dynamics of animal population time series. Proc. R. Soc. B: Biol. Sci. 278, 985-992.

Kreyling, J., 2010. Winter climate change: a critical factor for temperate vegetation performance. Ecology 91, 1939-1948.

Kurz, W.A., Dymond, C.C., Stinson, G., Rampley, G.J., Neilson, E.T., Carroll, A.L., Ebata, T. Safranyik, L., 2008. Mountain pine beetle and forest carbon feedback to climate change. Nature 452, 987-990.

Ladányi, M., Horváth, L., 2010. A review of the potential climate change impact on insect populations-general and agricultural aspects. Appl. Ecol. Environ. Res. 8, 143-152.

Limpert, E., Stahel, W.A., Abbt, M., 2001. Log-normal distributions across the sciences: keys and clues. Bioscience 51, 341-352.

Logan, J.A., Macfarlane, W.W., Willcox, L., 2010. Whitebark pine vulnerability to climate-driven mountain pine beetle disturbance in the Greater Yellowstone Ecosystem. Ecol. Appl. 20, 895-902.

Marini, L., Ayres, M.P., Battisti, A., Faccoli, M., 2012. Climate affects severity and altitudinal distribution of outbreaks in an eruptive bark beetle. Clim. Change 115, 327-341.

Massad, T.J., Dyer, L.A., 2010. A meta-analysis of the effects of global environmental change on plant-herbivore interactions. Arthropod-Plant Interact. 4, 181-188.

Nelson, W.A., Bjornstad, O.N.., Yamanaka, T., 2013. Recurrent insect outbreaks caused by temperature-driven changes in system stability. Science 341, 796-799.

Nibouche, S., Bues, R., Toubon, J.F., Poitout, S., 1998. Allozyme polymorphism in the cotton bollworm Helicoverpa armigera (Lepidoptera: Noctuidae): comparison of African and European populations. Heredity 80, 438-445.

Ouyang, F., Hui, C., Ge, S., Men, X.-Y., Zhao, Z.-H., Shi, P.-J., Zhang, Y.-S., Li, B.-L., 2014. Weakening density dependence from climate change and agricultural intensification triggers pest outbreaks: a 37-year observation of cotton bollworms. Ecol. Evol. 4, 3362-3374.

Ouyang, F., Liu, Z., Yin, J., Su, J., Wang, C., Ge, F., 2011. Effects of transgenic Bt cotton on overwintering characteristics and survival of Helicoverpa armigera. J. Insect Physiol. 57, 153-160.

Parmesan, C., Yohe, G., 2003. A globally coherent fingerprint of climate change impacts across natural systems. Nature 421, 37-42.

Peng, S.S., Chen, A.P., Xu, L., Cao, C.X., Fang, J.Y., Myneni, R.B., Pinzon, J.E., Tucker, C.J., Piao, S.L., 2011. Recent change of vegetation growth trend in China. Environ. Res. Lett. 6, 44027-44039.

Prendergast, A.C., 2008. IPCC-intergovernmental panel on climate change. Choice: Curr. Rev. Acad. Lib. 45, 1570-1571.

Richardson, A.D., Keenan, T.F., Migliavacca, M., Ryu, Y., Sonnentag, O., Toomey, M., 2013. Climate change, phenology, and phenological control of vegetation feedbacks to the climate system. Agric. For. Meteorol. 169, 156-173.

Roberts, A.M.I., Tansey, C., Smithers, R.J., Phillimore, A.B., 2015. Predicting a change in the order of spring phenology in temperate forests. Glob. Change Biol. 21, 2603-2611.

Rogers, L.A., 2011. Climate and population density drive changes in cod body size throughout a century on the Norwegian coast. Proc. Natl. Acad. Sci. U. S. A. 108, 1961-1966.

Root, T.L., Price, J.T., Hall, K.R., Schneider, S.H., Rosenzweig, C., Pounds, J.A., 2003. Fingerprints of global warming on wild animals and plants. Nature 421, 57-60.

Roy, D.B., Sparks, T.H., 2000. Phenology of British butterflies and climate change. Glob. Change Biol. 6, 407-416 410.

Schnoor, J.L., 2007. The IPCC fourth assessment. Environ. Sci. Technol. 41, 1503.

Shaver, G.R., Canadell, J., Chapin, F.S., Gurevitch, J., Harte, J., Henry, G., Ineson, P., Jonasson, S., Melillo, J., Pitelka, L., Rustad, L., 2000. Global warming and terrestrial ecosystems: a conceptual framework for analysis. Bioscience 50, 871-882.

Stenseth, N.C., Viljugrein, H., Saitoh, T., Hansen, T.F., Kittilsen, M.O., Bolviken, E., Glockner, F., 2003. Seasonality, density dependence, and population cycles in Hokkaido voles. Proc. Natl. Acad. Sci. U. S. A. 100, 11478-11483.

Tay, W.T., Soria, M.F., Walsh, T., Thomazoni, D., Silvie, P., Behere, G.T., Anderson, C., Downes, S., 2013. A brave new world for an old world pest: Helicoverpa armigera (Lepidoptera: Noctuidae) in Brazil. PLoS One 8, e80134. 
Taylor, F., 1986. Insect life histories: seasonal adaptations of insects. Science 232 1152.

Tryjanowski, P., Pawlikowski, T., Pawlikowski, K., Sparks, T.H., 2010. Does climate influence phenological trends in social wasps (Hymenoptera: Vespinae) in Poland? Eur. J. Entomol. 107, 203-208.

Turchin, P., 1999. Population regulation: a synthetic view. Oikos 84, 153-159.

Veteli, T.O., Kuokkanen, K., Julkunen-Tiitto, R., Roininen, H., Tahvanainen, J., 2002. Effects of elevated $\mathrm{CO}_{2}$ and temperature on plant growth and herbivore defensive chemistry. Glob. Change Biol. 8, 1240-1252.

Ward, N.L., Masters, G.J., 2007. Linking climate change and species invasion: an illustration using insect herbivores. Glob. Change Biol. 13, 1605-1615.
Wheeler, H.C., Hoye, T.T., Schmidt, N.M., Svenning, J.C., Forchhammer, M.C., 2015 Phenological mismatch with abiotic conditions-implications for flowering in Arctic plants. Ecology 96, 775-787.

Wu, K.M., Guo, Y.Y., 2005. The evolution of cotton pest management practices in China. Annu. Rev. Entomol. 50, 31-52.

Wu, K.M., Lu, Y.H., Feng, H.Q., Jiang, Y.Y., Zhao, J.Z., 2008. Suppression of cotton bollworm in multiple crops in China in areas with Bt toxin-containing cotton. Science 321, 1676-1678.

Yang, L.H., Rudolf, V.H.W., 2010. Phenology, ontogeny and the effects of climate change on the timing of species interactions. Ecol. Lett. 13, 1-10.

Zilberman, D., Liu, X., Sunding, D., 2002. The Impact of Climate Change on Agriculture: A Global Perspective. Springer, US, pp. 423-438. 